REVISTA DE GEOCIÊNCIAS DO NORDESTE

Northeast Geosciences Journal

v. $6, \mathrm{n}^{\circ} 2(2020)$

ISSN: $2447-3359$

https://doi.org/10.21680/2447-3359.2020v6n2ID18357

\title{
PROPOSTA DE UMA CARTA GEOTÉCNICA PRELIMINAR DE FUNDAÇÕES PARA A REGIÃO CENTRO-NORTE DE FORTALEZA-CE
}

\section{Helano Wilson Pimentel ${ }^{1}$; Alfran Sampaio \\ Moura $^{2}$; Andressa de Araujo Carneiro ${ }^{3}$}

\author{
${ }^{1}$ Mestre em Geotecnia, Departamento de Engenharia \\ Hidráulica e Ambiental (UFC), Fortaleza/CE, Brasil. \\ ORCID: https://orcid.org/0000-0001-6656-7729 \\ Email: helanowilson@ufc.br
}

${ }^{2}$ Doutor em Geotecnia, Departamento de Engenharia Hidráulica e Ambiental (UFC), Fortaleza/CE, Brasil.

ORCID: https://orcid.org/0000-0002-0303-2484

Email: alfransampaio@ufc.br

${ }^{3}$ Doutora em Geotecnia, Departamento de Recursos Hídricos, Geotecnia e Saneamento Ambiental (UFPI), Teresina/PI, Brasil.

ORCID: https://orcid.org/0000-0001-9571-2913

Email: andressa.deac@gmail.com

\section{Resumo}

O artigo trata da estruturação do banco de dados de informações geotécnicas georeferenciado e elaboração de uma carta preliminar de fundações refente a região centro-norte da cidade de Fortaleza. Utilizando o software Google Earth, foi coletado 395 furos de sondagens à percussão em empresas locais e delineado 23 regiões. A partir de um tratamento estatístico, traçou-se mapas de isovalores de NSPT nas profundidades de 2, 5 e $10 \mathrm{~m}$, do Nível d'água (NA) e para cada região foi determinada, ainda, uma sondagem representativa. Após estabelecido três portes de edificações elaborou-se uma carta preliminar de fundações. Conclui-se que o sistema utilizado no georeferenciamento dos dados coletados é adequado, possui fácil manuseio e utiliza arquivos de pequeno tamanho. Considerando edificações de pequeno porte, na maioria das vezes, pode-se utilizar fundações do tipo sapata assente a pequenas profundidades. Para edificações de médio e grande porte recomenda-se o uso de estacas e estimase, preliminarmente, comprimentos que variam com o posicionamento da região.

Palavras-chave: Sondagens; Caracterização geotécnica; Fundação.

\section{PROPOSAL OF A PRELIMINARY GEOTECHNICAL MAP OF FOUNDATIONS IN THE CENTER-NORTH REGION OF FORTALEZA-CE.}

\begin{abstract}
The article deals with the structuring of georeferenced geotechnical information database and the elaboration of a preliminary foundation letter that reflects the north-central region of the city of Fortaleza. Using the Google Earth software, 395 drill holes were collected percussion at local companies and outlined 23 regions, from the statistical treatment, maps of NSPT isovalors were plotted at depths of 2,5 and $10 \mathrm{~m}$, at water level the representative survey. After establishing three lots of buildings, a preliminary list of foundations was drawn up. It is concluded that the system used in the georeferencing of the collected data is adequate, has an easy handling and uses small files. Considering small buildings, almost always, it is possible to use foundations of the type shoe based to small depths. Medium and large buildings it is estimated, preliminarily, lengths varying with positioning of the region.
\end{abstract}

Keywords: Drillings; Geotechnical characterization; Foundation.

\section{PROPUESTA DE UNA CARTA GEOTÉCNICA PRELIMINAR PARA FUNDACIONES PARA LA REGIÓN CENTRO-NORTE DE FORTALEZA-CE.}

\section{Resumen}

El artículo aborda la estructuración de la base de datos de información geotécnica georreferenciada y la preparación de una carta preliminar de fundaciones que hace referencia a la región centro-norte de la ciudad de Fortaleza. Usando el software Google Earth, se recogieron 395 agujeros de sondaje a percusión de compañías locales y se describieron 23 regiones. A partir de un tratamiento estadístico, se dibujaron mapas de isovalores NSPT a profundidades de 2,5 y $10 \mathrm{~m}$, desde el nivel del agua (NA) y para cada región, también se determinó una encuesta representativa. Después de establecer tres tamaños de edificios, se preparó una carta preliminar de cimientos. Se concluye que el sistema utilizado en la georreferenciación de los datos recopilados es adecuado, tiene un manejo fácil y utiliza archivos pequeños. Teniendo en cuenta los edificios pequeños, la mayoría de las 
veces, puede usar cimientos tipo zapato basados en pequeñas profundidades. Para edificios medianos y grandes, se recomienda el uso de pilotes y se estiman longitudes preliminares que varían con el posicionamiento de la región.

Palabras-clave: Sondaje; Caracterización geotécnica; Fundación.

\section{INTRODUÇÃ̃O}

A cartografia geotécnica pode ser utilizada como importante ferramenta de contribuição para o avanço científico e tecnológico de diversas áreas da ciência. $\mathrm{Na}$ engenharia civil permite, por exemplo, o uso de dados geotécnicos, desde o planejamento até a execução de uma obra de construção civil. A cartografia geotécnica é um processo que tem como objetivo caracterizar o meio físico (ZUQUETTE,1987). Os dados obtidos devem passar por estágios de seleção, generalização, adição e transformação, permitindo correlações, e que devem ser interpretados de tal forma que possam ser representados em mapas e cartas. Através dessas representações o usuário pode analisar o meio físico e tomar uma série de decisões.

O grande número de edificações construídas em Fortaleza, nas últimas décadas gerou uma quantidade significativa de informações geotécnicas do subsolo da cidade realizadas por empresas que atuam na área geotécnica. Neste contexto, essas informações podem ser utilizadas na elaboração de cartas geotécnicas, como as cartas de fundações, que podem auxiliar tanto na orientação quanto no uso e ocupação de áreas em expansão das diversas regiões de Fortaleza.

Portanto, o ensaio de sondagem à percussão é um processo de exploração e reconhecimento do subsolo, bastante utilizado na Engenharia Civil, e que fornece uma série de informações necessárias à realização de projetos de fundações. O ensaio SPT (Standard Penetration Test) é o mais utilizado pelos projetistas de fundações no Brasil devido ao seu baixo custo, fácil manuseio e por fornecer dados como o índice de resistência à penetração (NSPT), identificação da profundidade do nível d'água, descrição da estratigrafia do subsolo e obtenção de amostras deformadas. A NBR 6484 (ABNT, 2001) é a norma que regulamenta a execução desse ensaio no Brasil.

Borges (2019) analisa a utilização da estatística descritiva, geoestatística e estatística multivariada para realizar o mapamento geotécnico da cidade de Rio Branco-Acre. Para isso utilizou uma série de atributos, dentre eles, resultados de sondagens à percussão (SPT).

Thiesen (2016) discute e analisa a utilização de sistemas de informação geográfica no tratamento e processamento de dados geotécnicos georreferenciados para a elaboração do mapeamento geotécnico do município de Blumenau/SC e de mapas de aptidão para fundação a partir de 537 sondagens à percussão. Os resultados mostraram-se válidos não somente por possibilitar a aplicação prática de manipulação e modelagem do banco de dados em ambiente SIG, mas também por propiciarem resultados estratégicos para tomada de decisão, orientando e fornecendo informações em linguagem técnica.

Nascimento e Larios (2020) diante da necessidade da execução de investigações de subsolo, propõem a utilização de uma biblioteca de perfis de sondagens para a criação de uma série de cartas geotécnicas. Estas cartas são elaboradas por meio de uma aplicação digital alimentada com dados da resistência à penetração do subsolo dentro da área de estudo do Centro Universitário Adventista de São Paulo. O software exibe os números de golpes registrados no Standard Penetration Test (SPT) por camadas e o nível da água subterrânea em dados estatisticamente confiáveis, facilitando o projeto de fundações para novas edificações. Os autores realizaram teste estatístico de $\mathrm{X}^{2}$ e os resultados obtidos foram confiáveis, onde todas as camadas analisadas comprovam não haver diferenças significativas quando comparadas aos perfis de sondagens reais.

Os mapas não podem substituir uma investigação detalhada local, mas podem ajudar na fase de anteprojeto da investigação local e na interpretação dos resultados (SILVA, 2011). Já cartas, podem abordar diversos problemas generalizados e serem úteis nas primeiras etapas do planejamento, como também nos estágios finais dos projetos de engenharia.

Este trabalho visa uma estruturação de um banco de dados de informações geotécnicas georeferenciadas e elaboração de uma carta preliminar de fundações de uma área situada na região centro-norte da cidade de Fortaleza-CE e tem como objetido o fornecimento de informações que possam ser úteis na orientação de futuras investigações geotécnicas. Além disso, as informações constantes neste presente estudo indicarão, preliminarmente, o tipo de fundação a se utilizar, de acordo com o porte da futura edificação possibilitando, portanto, informações úteis para o planejamento da futura obra.

\section{CARACTERIZAÇÃO DO MEIO FÍSICO DE FORTALEZA}

O Município de Fortaleza localiza-se em uma planície litorânea na porção norte do estado do Ceará, no nordeste do Brasil, possuindo $32 \mathrm{~km}$ de linha de costa. Esta por sua vez está limitada ao norte com o oceano Atlântico; ao sul com os Municípios de Maracanaú, Itaitinga e Pacatuba; no sentido oeste com Eusébio e Aquiraz; e a leste com o Município de Caucaia.

A cidade de Fortaleza é um dos principais centros urbanos do Estado do Ceará, reunindo o maior contingente populacional do Estado, ocupando assim a posição de quinta maior cidade do Brasil, com população de 2.447.409 habitantes (INSTITUTO BRASILEIRO DE GEOGRAFIA E ESTATÍSTICA, 2011). É uma cidade que cresce verticalmente, principalmente na zona litorânea, contudo, o aumento de edifícios em bairros periféricos encontram-se em expansão considerável.

A topografia suave do relevo das terras de Fortaleza permitiu um traçado ortogonal quase perfeito de suas ruas, especialmente as que constituem o Centro de Fortaleza.

A região de Fortaleza é caracterizada pela presença de rochas cristalinas (metamórficas e ígneas), sedimentos de idade terciária, além de sedimentos transportados como colúvio e alúvio além da presença de dunas (COLARES, 1996) e segundo Fonteles (2003), Fortaleza é dividida em quatro regiões geológicas: Formação Barreiras; Paleodunas; Sedimentos Aluvionares e Dunas.

A Formação Barreiras caracteriza-se pelo acúmulo de detritos areno-argilosos, com granulometria de média a fina, abrangendo largura variável a partir do litoral e profundidade irregular em grande área da Região Metropolitana de Fortaleza (CHAVES, 2000). 
Na Região Metropolitana de Fortaleza observa-se que a Formação Barreiras, estende-se em direção ao maciço de Baturité, alcançando muitos bairros de Fortaleza, além de, praticamente todo o município de Caucaia e Eusébio. Os solos da Formação Barreiras possuem formato sub-arredondados, tratam-se de sedimentos areno-argiloso, de coloração avermelhada, creme ou amarelada, frequentemente com aspecto mosqueado, mal selecionados, possuindo níveis conglomeráticos, matriz argilosa caulinítica com cimento argilo-ferruginoso e por muitas vezes silicoso (BARROSO, 2002).

Quanto a formação pedológica, possuem areias quartzosas distróficas e podzólicos vermelho-amarelos distróficos, ocorrendo em dois contextos estruturais distintos, sob a forma de estratos horizontalizados e não deformados, ou a situação mais usual, constituindo camadas basculadas e afetadas por forte deformação.

A Formação Barreiras está caracterizada por uma expressiva variação faciológica, o que lhe confere parâmetros hidrogeológicos diferenciados, pois, apresenta alternância de níveis com distintas condutividades hidráulicas.

Os sedimentos aluvionares correspondem aos depósitos arenosos e argilosos que ocorrem margeando os baixos cursos de rios, como o Rio Cocó. O solo dessa região quase sempre é composto por areia mal selecionada variando de granulometria média a grossa (BRASIL, 1998). Além de aluviões e depósitos de planícies de inundação, nessa região encontram-se depósitos flúvio-marinhos compostos por areia, cascalhos, siltes e argila com ou sem matéria orgânica (FONTELES, 2003).

As dunas, formadas a partir da remoção da face de praia pela deflação eólica, compreendem sedimentos inconsolidados formando um cordão litorâneo de 2 à $3 \mathrm{~km}$ de largura e no máximo, 30 metros de altura, dispostos paralelamente a linha de costa e são constituídas por areias quartzosas, amarelada a esbranquiçada, granulometria fina a média, com grãos bem selecionados, foscos, que variam de arredondados a subarredondados. Podem-se observar grãos de afrisita, zircão, monazita e ilmenita. As dunas móveis (sem a vegetação fixadora) podem ocasionar, pelo retrabalhamento do fluxo de sedimentos, um assoreamento de pequenos canais fluviais e/ou impedirem que alguns cursos d'água alcancem o oceano, favorecendo o aparecimento de lagoas interdunares, alterando a configuração da costa. (FONTELES, 2003).

Os solos da região de Fortaleza apresentam características geotécnicas bem definidas que influenciam o projeto e a execução das obras de engenharia que são importantes em relação ao suporte das fundações das edificações (MIRANDA, 2005).

A região das rochas cristalinas apresentam três níveis horizontais distintos. O primeiro, superficial, é caracterizado como arenoso-argiloso com a presença de pedregulhos, de coloração marrom, com presença de raízes e matérias orgânicas. O segundo nível, composto por um solo residual maduro, caracteriza-se como areia argilosa com pedregulhos, de coloração variavél entre amarela e vermelha. Já o terceiro horizonte, conhecido por solo residual jovem (ou horizonte saprolítico), possui aparência da rocha gnáissica com frações de areia, silte e argila.

As estacas pré-moldadas de concreto, hélice contínua, Franki e tubulões geralmente se apoiam sobre o horizonte saprolítico (MIRANDA, 2005). Quando utiliza-se estacas raízes, cuja execução requer o uso de perfuratrizes rotativas e de estacas metálicas, por conta das elevadas capacidades e reduzidas seções, elas conseguem ultrapassar essa camada (terceiro horizonte) e atingem a rocha.

Na região da Formação Barreiras, os solos são constituídos por areia, silte e argila em variadas proporções além de níveis ricos em cascalho, com camadas de areias argilosas, areias siltosas e argilas areno-siltosas, de coloração cinza claro ao vermelho, passando por amarelo e laranja (BRAGA, 2009). Em cotas próximas do nível do mar existem camadas conglomeráticas e laterizadas formando arenitos de cimento ferruginoso. Essas camadas são de fundamental importância para definição do tipo de fundação em obras próximas à beira-mar. No caso das estacas metálicas, a cravação é geralmente interrompida ao atingir estas camadas (MIRANDA, 2005).

Colares (1996), elaborou uma carta geotécnica da Região Metropolitana de Fortaleza, através de um conjunto de documentos cartográficos resultando em um mapeamento geotécnico preliminar, que dividiu toda a região de acordo com suas características geotécnicas, apresentando os seguintes produtos: Mapa de documentação; Carta de declividade; Mapa de Landforms; Mapa de Substrato Rochoso; Mapa de Materiais Inconsolidados; Mapa das Áreas com Problemas Ambientais; Carta de Recursos Hídricos e Carta de Zoneamento Geotécnico Preliminar.

A Carta de Zoneamento Geotécnico Preliminar foi elaborada a partir da superposição dos mapas de substrato rochoso, de materiais inconsolidados e da carta de declividade com o objetivo de individualizar as unidades geotécnicas. Essa carta define as possibilidades de uso e ocupação do meio físico destas unidades.

Moura (1997), realizou um trabalho visando à caracterização geotécnica preliminar de uma área situada na região nordeste de Fortaleza, apresentando modelos digitais referentes a estratigrafia do solo na área do posicionamento do nível da água. Além disso, o autor apresenta um estudo estatístico para representar o NSPT no espaço e ao longo da profundidade. Uma avaliação da aplicabilidade de métodos semi-empíricos para a determinação da capacidade de carga de estacas pré-moldadas e metálicas também foi realizada.

Fonteles (2003), utilizou a mesma carta geotécnica de Colares (1996), no entanto, estudou apenas uma parte da capital cearense, modificando o código adotado e criando uma nova sequência numérica para representação de cada região de acordo com suas características geotécnicas. Essa divisão de Fortaleza, Figura 1, serviu de base para a presente pesquisa. 


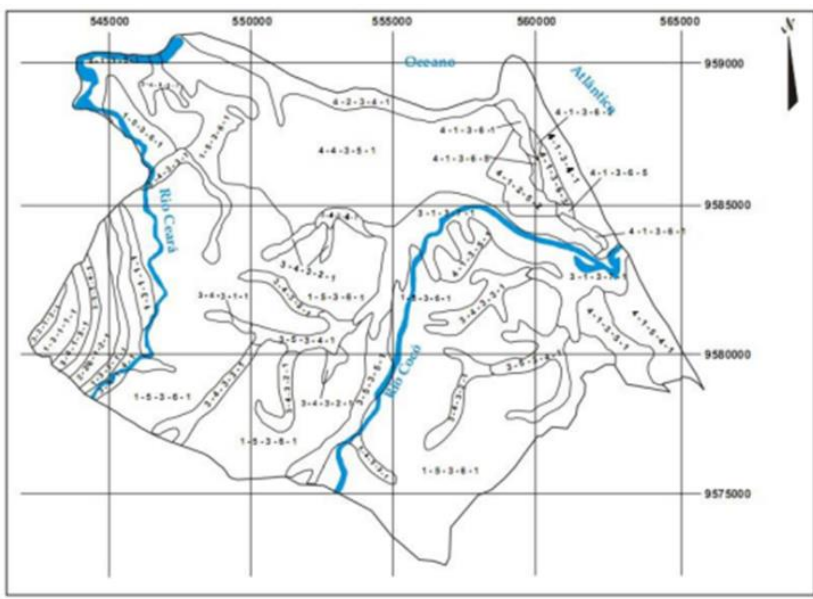

Figura 01 - Mapa de Zoneamento Geotécnico preliminar de Fortaleza. Fonte: Fonteles (2003).

Com intuito de orientar a sociedade quanto ao uso e ocupação de áreas de expansão, Martins (2005) elaborou cinco documentos cartográficos básicos: mapa de documentação; mapa de substrato rochoso; mapa pedológico; mapa de profundidade do nível d'agua freática e carta de declividade. Como produto final, apresentou uma carta de unidades geotécnicas que evidencia as caraterísticas da região estudada.

\section{METODOLOGIA}

A metodologia adotada para a realização da presente pesquisa está baseada na execução das seguintes etapas: coleta de dados; digitalização, análise e pesquisa de endereço de cada relatório de sondagem; estruturação de um sistema para armazenamento dos dados de sondagens; subdivisão da cidade de fortaleza; tratamento geo-estatístico; aplicação de modelos geoestatístico e execução de uma carta de fundações.

Os dados coletados para a realização desse trabalho correspondem a 220 relatórios de sondagens à percussão (SPT), totalizando 395 furos selecionados que foram digitalizados e inseridos em um sistema utilizando a ferramenta Google Earth. Posteriormente, esses dados foram sobrepostos ao mapeamento geotécnico proposto por Colares (1996) e inseridos no presente sistema.

Os índices de sondagem à percussão (NSPT) foram inseridos na pesquisa utilizando-se o software Surfer 8, possibilitando a geração de mapas de isovalores de NSPT nas profundidades de $2 \mathrm{~m}, 5 \mathrm{~m}$ e $10 \mathrm{~m}$. As sondagens à percussão (SPT) coletadas foram utilizadas para determinar os perfis de sondagem à percussão representativos de 23 regiões, atráves de um tratamento estatístico, situadas na porção centro-norte da cidade de Fortaleza-CE.

Na sequência, as sondagens representativas obtidas para cada uma das 23 regiões foram utilizadas para elaboração de uma carta preliminar de fundações considerando-se três diferentes portes de edificações: pequeno, médio e grande. Foram consideradas obras de pequeno porte as edificações de apenas 1 pavimento, as de médio porte são as edificações de 4 pavimentos e de grande porte as edificações de 10 pavimentos, ou mais, além do subsolo.
Vale mencionar que o presente artigo aborda a pesquisa de mestrado de Pimentel (2015), na qual maiores detalhes podem ser obtidos.

\section{APRESENTAÇÃO E ANÁLISE DOS RESULTADOS}

\author{
4.1. Banco de dados georeferenciado de informações \\ geotécnicas
}

O georeferenciamento das 220 sondagens à percussão (SPT) coletadas e utilizadas nesse trabalho utilizando o software Google Earth, é exposto a seguir (Figura 2). Observa-se também na mesma figura que foram coletados dados de diversas regiões de Fortaleza, constatando-se também que há uma elevada quantidade de sondagens situadas região centro-norte da cidade. Dessa forma, a carta geotécnica de fundações e os mapas de isovalores foram direcionados para essa porção da cidade. Vale mencionar que, no sistema utilizado, a visualização do perfil de sondagem de cada ponto locado no mapa pode ser realizada simplesmente clicandose no ponto selecionado.

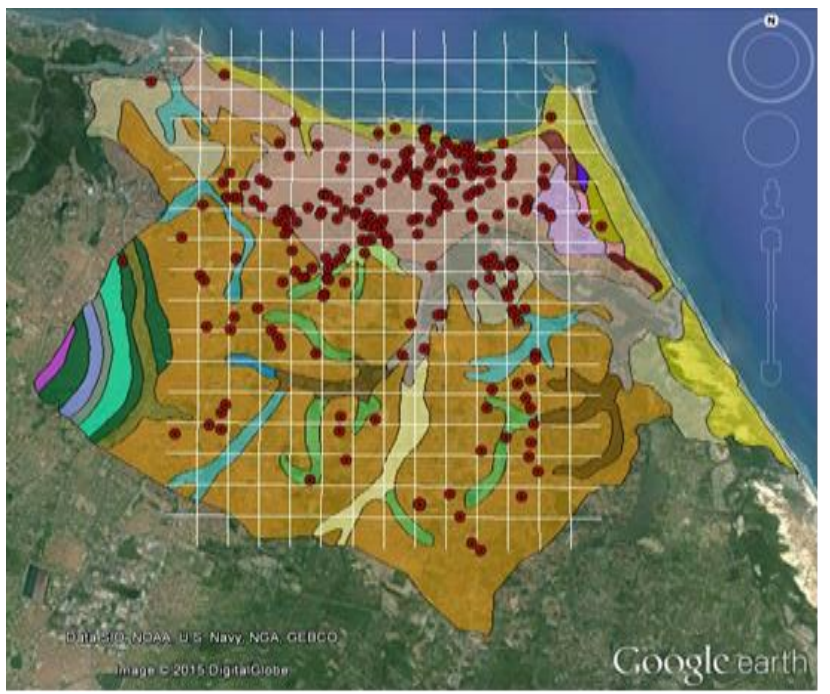

Figura 02 - Locação esquemática das sondagens utilizadas no trabalho. Fonte: Pimentel (2015).

\subsection{Subdivisão da cidade de FortalezaBanco de dados georeferenciado de informações geotécnicas}

Inicialmente a cidade de Fortaleza, foi subdividida a partir das indicações da Carta de Zoneamento Geotécnico Preliminar elaborada por Fonteles (2003) e inserida no software Google Earth, através de transformação de arquivos .dwg para .kml. Vale observar que, na Figura 2, regiões de mesmas características geotécnicas (origem, textura, tipo de substrato rochoso, espessura dos materiais inconsolidados e classes de declividade) são representadas com a mesma tonalidade de cor.

Com intuito de dividir o município de Fortaleza em áreas de $1 \mathrm{~km}^{2}$ inseriu-se uma malha de acordo com as coordenadas geográficas UTM, sendo que cada área, quadrada, foi definida pelas linhas da própria malha. 
Desta forma, com as informações fornecidas por Fonteles (2003) e com a inserção dos resultados dos 220 relatórios de sondagens foi possível estabelecer as áreas com características consideradas homogêneas em termos geotécnicos (Figura 3). Para utilizar a área no desenvolvimento do trabalho foram considerados ainda os seguintes critérios: cada área estudada deve apresentar, no mínimo, 3 sondagens à percussão (SPT) e cada área deve estar posicionada, obrigatoriamente, em uma mesma unidade geotécnica delimitada por Fonteles (2003).

São observadas 23 regiões (Figura 3), que atendem aos critérios estabelecidos para a subdivisão das áreas e que, portanto, correspondem as áreas selecionadas para compor a carta geotécnica preliminar proposta neste trabalho.

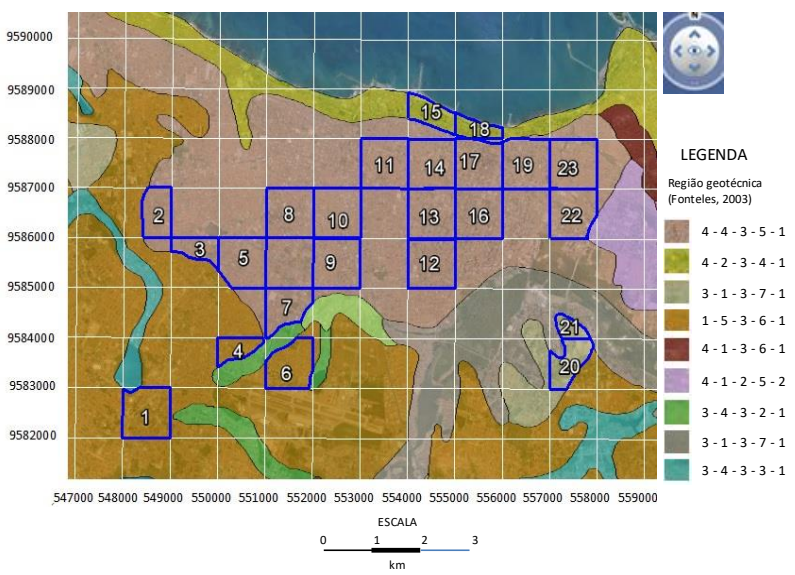

Figura 03 - Definição das 23 regiões de estudo do trabalho. Fonte: Pimentel (2015).

\subsection{Sondagens representativas}

Em cada região da Figura 2 foi realizado um tratamento estatístico para determinar um perfil de sondagem representivo. Para tanto, a cada metro de profundidade utilizou-se os valores de índice de resistência à penetração (NSPT) médios, máximos e mínimos dos furos localizados no interior da região. A sondagem que apresentou o menor somatório dos resíduos em relação à média foi considerada a sondagem representativa de cada região.

Para ilustrar o procedimento adotado considerou-se os perfis de sondagens de números 9; 12; 41; 96 e 206 localizados internamente à região 18 . Dentre esses perfis o que apresentou o menor somatório dos resíduos em relação à média foi o perfil de número 96. Desta forma, o perfil de sondagem de número 96 foi o utilizado para a escolha dos tipos de fundações em função do porte de cada obra e que serão apresentados na carta preliminar de fundação proposta nesta pesquisa.

O mesmo processo foi adotado nas demais regiões representadas na Figura 3, desta forma, foram obtidos 23 perfis de sondagens representativos. Sendo que cada perfil representativo contém a estratigrafia do subsolo, a profundidade do nível da água e os valores de NSPT ao longo da profundidade. A representação gráfica de cada uma dos 23 perfis de sondagens representativos estão disponíveis em Pimentel (2015).

\subsection{Mapas de isovalores do NSPT e N.A ( Nível da água) para a região centro-norte de Fortaleza}

Com os valores do NSPT das sondagens representativas e com o auxilio do software Surfer versão 8.0, foram construídos mapas de isovalores do NSPT nas profundidades 2,5 e $10 \mathrm{~m}$. Nas Figura 4, 5 e 6 são apresentados os mapas de isovalores gerados do NSPT para a profundidades mencionadas e na Figura 7 é possível observar o mapa de isovalores do N.A.

Por meio das Figuras 4 a 6 observa-se que, na profundidade de $2 \mathrm{~m}$ o NSPT ao longo da área estudada é significativamente inferior e, quase sempre, não excede 7 golpes (Figura 4). Para a profundidade de $5 \mathrm{~m}$, há uma área mais ampla apresentando NSPT variando de 5 a 10 golpes (Figura 5). Nesta mesma profundidade, valores acima de 30 golpes praticamente não foram observados. Já para a profundidade de 10 m o NSPT supera 14 golpes em cerca de $75 \%$ da área analisada (Figura 6).

Pela Figura 7 observa-se que, na região estudada, o nível d'água (NA) apresenta-se entre as profundidades de 2 a $12 \mathrm{~m}$. Foi observado ainda que a profundidade do nível d'água varia em função da estratigrafia do solo e topografia da supefície. Apenas pontualmente a profundidade do NA atinge valores mais elevados.

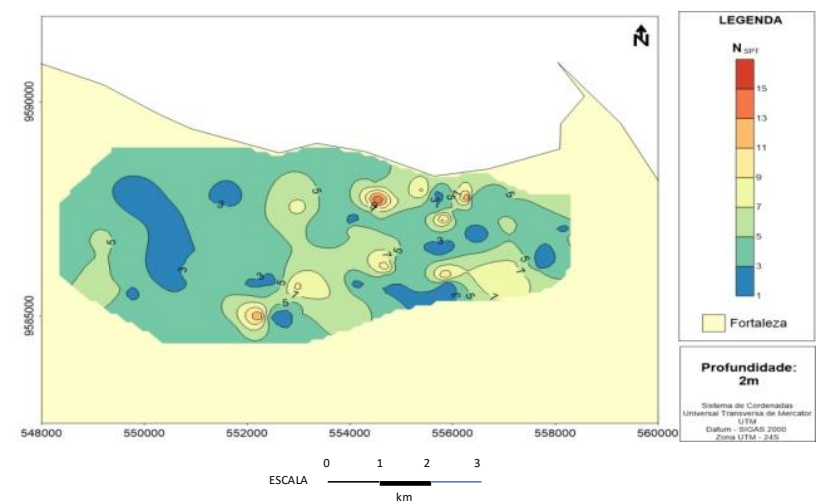

Figura 04 - Mapa de isovalor de NSPT na profundidade de $2 \mathrm{~m}$. Fonte: Pimentel (2015).

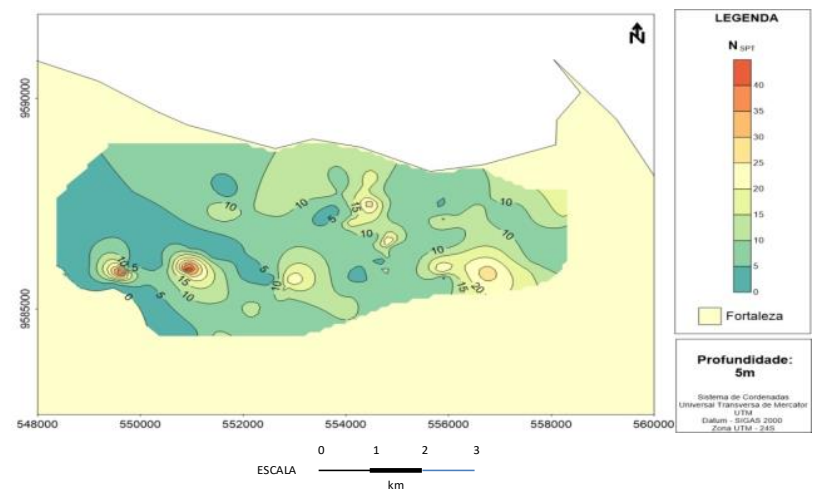

Figura 05 - Mapa de isovalor de NSPT na profundidade de $5 \mathrm{~m}$. Fonte: Pimentel (2015). 


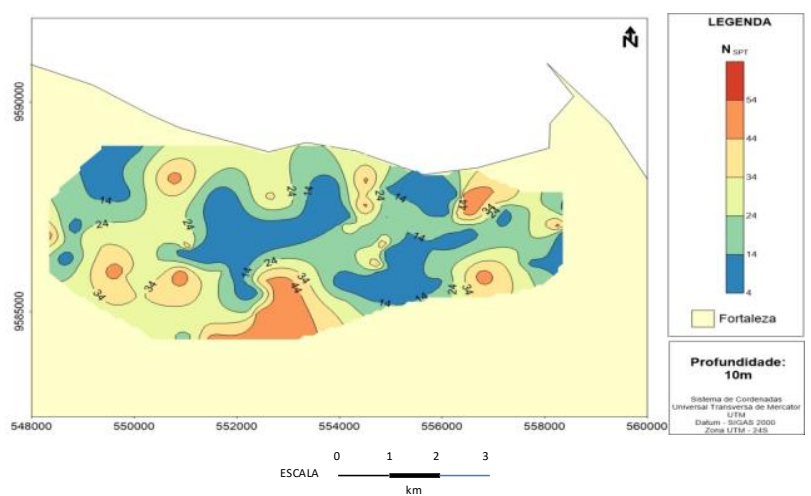

Figura 06 - Mapa de isovalor de NSPT na profundidade de $10 \mathrm{~m}$. Fonte: Pimentel (2015).

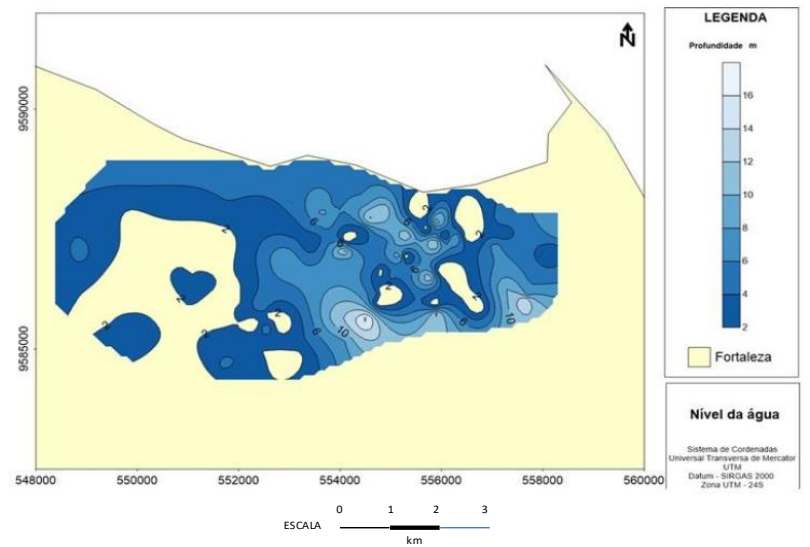

Figura 07 - Mapa de isovalores do N.A. Fonte: Pimentel (2015).

\subsection{Carta geotécnica preliminar de fundações da região centro-norte de Fortaleza-CE}

Considerando as 23 sondagens à percussão representativas da área mapeada, foi gerada uma carta geotécnica com indicativo preliminar do tipo de fundação mais apropriado para cada região analisada, de acordo com três portes de edificações: pequeno porte (edificação de apenas 1 pavimento); médio porte (edificação com no máximo 4 pavimentos); e grande porte (edificações com 10 andares, além do subsolo).

Para as edificações de pequeno porte foi analisada a possibilidade de utilizar uma fundação superficial do tipo sapata, ou radier, e a correspondente profundidade de assentamento. $\mathrm{O}$ presente trabalho tem pretensão de fornecer informações apenas a nível de anteprojeto, portanto foram consideradas apenas formulações empíricas chamadas localmente de fórmulas "práticas", para determinação da taxa admissível (oadm) dos solos a partir do índice de resistência (NSPT) médio na provável profundidade do bulbo de tensões. Desta forma, para perfis de solos predominantemente arenosos utilizou-se a Equação 1, e a Equação 2 para os casos de solos argilosos.

$$
\begin{gathered}
\sigma_{a d m}=\frac{N_{S P T}}{5} \\
\sigma_{a d m}=\frac{N_{S P T}}{8}
\end{gathered}
$$

Onde:

NSPT - é o índice de resistência médio no bulbo de pressão бadm - taxa admissível do solo expresso em $\mathrm{kgf} / \mathrm{cm} 2$

Para as edificações consideradas de médio porte, conforme características descritas anteriormente, foram analisadas a utilização de estacas pré-moldadas de concreto possuindo pequena dimensão (seção quadrada $25 \mathrm{~cm}$ x $25 \mathrm{~cm}$ ) utilizando-se os seguintes métodos semi-empíricos para a determinação do comprimento das estacas: Aoki e Velloso (1975) e Décourt e Quaresma (1978). Para esta estaca a carga de trabalho considerada foi de $400 \mathrm{kN}$ (Velloso e Lopes, 2010). As situações que apresentassem divergência entre os métodos, relacionadas ao comprimento das estacas, foi adotado o método de Aoki e Velloso (1975).

No caso de edificações de grande porte, conforme as características descritas anteriormente, foi estimado o comprimento de 2 tipos de estacas, hélice e raiz, considerando uma carga de trabalho de $550 \mathrm{kN}$, quando utilizado estacas raiz de diâmetro $250 \mathrm{~mm}$, e cargas de trabalho com $1700 \mathrm{kN}$ para uso de estacas hélice de $600 \mathrm{~mm}$ de diâmetro. Para estimativa do comprimento da estaca raiz foram analisados dois métodos: Cabral (1986) e Aoki e Velloso (1975), com modificações de Monteiro (1997). Para determinar o comprimento das estacas hélices foram utilizados os seguintes métodos: Antunes e Cabral (1996) e Aoki e Velloso (1975), também com modificações de Monteiro (1997). No caso de divergência entre os métodos, quanto ao comprimento das estacas, foram considerados os métodos específicos de cada tipo de estaca, ou seja, o método de Cabral (1986), para estacas raiz, e o método de Antunes e Cabral (1996) para determinação das estacas hélices.

Apresenta-se na Figura 8 a representação esquemática da carta geotécnica preliminar de fundações da região centro-norte de Fortaleza, gerada na escala 1:25.000. Vale mencionar que, a carta de fundações completa está disponível em Pimentel (2015).

Em 20 das 23 regiões estudadas é indicado o uso de fundação do tipo sapata, assentes a $1 \mathrm{~m}$ de profundidade, em obras de pequeno porte. No entanto, há uma variação na taxa admissível do solo de $50 \mathrm{kPa}$ a $170 \mathrm{kPa}$. Em apenas três regiões estudadas avaliou-se preliminarmente que sapatas assentes em profundidades superficiais não suportaria obras de pequeno porte, devido a baixa taxa admissível estimada.

Nas obras de médio porte, naquelas regiões em que foi recomendado o uso de estacas pré-moldadas de concreto, de 25 $\mathrm{cm}$ x $25 \mathrm{~cm}$, das 23 áreas estudadas, em 10 áreas o comprimento das estacas variou de 10 a $12 \mathrm{~m}$. Apesar de existirem áreas localizadas em uma mesma unidade geotécnica, segundo as indicações de Fonteles (2003), foi observada uma variação considerável nos comprimentos desse tipo de estaca, como no 
caso da região 14 com indicativo de $4 \mathrm{~m}$ de comprimento da estaca e a região 11, na mesma unidade geotécnica, com $16 \mathrm{~m}$ de comprimento da estaca. Essa variação de comprimento é atribuída à acentuada variação do NSPT ao longo da profundidade entre regiões situadas em uma mesma unidade geotécnica.

Para as duas regiões localizadas na unidade geotécnica 4-2-34-1, segundo Fonteles (2003), em obras de grande porte são indicadas estacas raiz de $250 \mathrm{~mm}$ de diâmetro, com comprimentos variando entre 9 e $10 \mathrm{~m}$. Da mesma forma, as regiões localizadas na unidade geotécnica 4-1-3-5-4-1, definidas por Fonteles (2003), também possuem indicativo de comprimento semelhantes nos casos de estacas raiz, variando entre 13 a $15 \mathrm{~m}$. No entanto, na unidade 4-4-3-5-1, que concentra a maior quantidade de regiões analisadas, há uma variação do comprimento das estacas raiz variando de 7 a $16 \mathrm{~m}$ de comprimento.

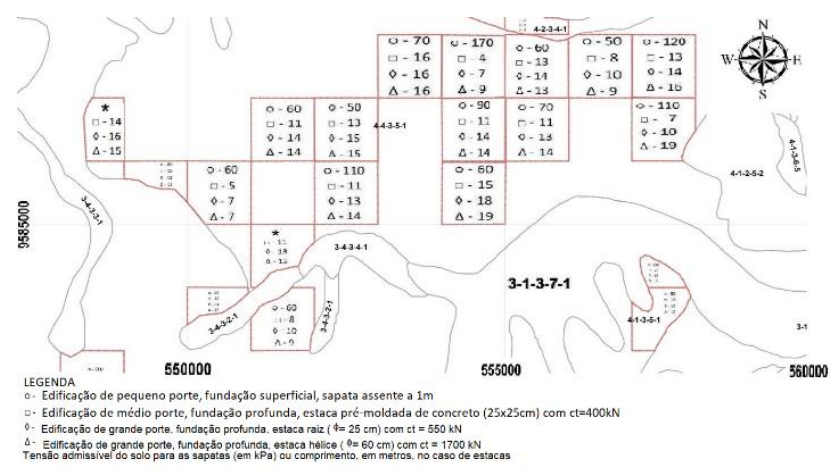

Figura 08 - Representação esquemática da carta geotécnica preliminar de fundações da região centro-norte de Fortaleza. Fonte: Pimentel (2015).

Nos casos de obras de grande porte, conforme descrito anteriormente, o uso de estacas hélice, de $600 \mathrm{~mm}$ de diâmetro, foi a que apresentou a maior variação de comprimento, tanto para regiões localizadas em uma mesma unidade geotécnica como inseridas em unidades diferentes. A variação está entre 7 e 19 m de comprimento. No entanto em 14, das 23 regiões estudadas, é sugerido a adoção de estacas hélice com comprimento de 12 a 16 m.

\section{CONCLUSÕES}

A utilização de recursos de informática ampliaram os limites da ciência. Na Engenharia, o uso de ferramentas digitais colabora para uma elavação da velocidade de elaboração de projetos, otimizando o tempo e, portanto, o custo das obras. Nesse contexto, a disponibilização de dados geotécnicos através de mapas digitais proporcionam rapidez e praticidade para construtores, estudantes, pesquisadores e a sociedade em geral.

A metodologia proposta mostrou-se adequada para o trabalho realizado. Os arquivos gerados são de pequeno tamanho, podendo ser manipulados facilmente por e-mail ou outra mídia de memória. Embora algumas regiões delimitadas nesse trabalho estejam situadas em uma mesma unidade geotécnica definida por Fonteles (2003), foi observado perfis de resistência (NSPT) bastante variáveis, em alguns casos.
Por outro lado, tomando como base de comparação os gráficos de cada uma das 23 regiões estudadas verifica-se que, para uma mesma profundidade não houve variação significativa do NSPT dentro de uma mesma região delimitada, indicando coerência entre a metodologia adotada e a homogeneidade de comportamento, em termos de NSPT de cada região.

Considerando ainda uma mesma profundidade, verifica-se que o NSPT varia significativamente no espaço e observa-se que essa variação é ainda maior entre regiões situadas em unidades geotécnicas diferentes.

Ao longo da profundidade, como esperado, a variação de NSPT em uma mesma região é acentuada e entre regiões distintas é ainda maior.

Considerando-se a carta de fundações gerada, conclui-se que é possível a adoção de fundações superficiais, assentes para pequenas profundidades, em obras de pequeno porte. Em casos que não seja viável, uma alternativa, seria adotar estacas curtas pré-moldadas, de $25 \mathrm{~cm} \times 25 \mathrm{~cm}$, caso as vibrações decorrentes da execução dessa alternativa nas áreas adjacentes não inviabilize seu uso.

Para os casos de obras de médio porte foi observado preliminarmente a necessidade de adoção de fundações profundas. Caso a vizinhança permita, sugere-se uso de estacas pré-moldadas de concreto, também de $25 \mathrm{~cm}$ x $25 \mathrm{~cm}$. Em quase metade das regiões consideradas o comprimento dessas estacas variou de 10 a $12 \mathrm{~m}$.

Ainda para obras de porte médio, em algumas regiões, situadas na mesma unidade geotécnica, definida por Fonteles (2003), foram estimados comprimentos com variação elevada, tal fato atribui-se à variação de NSPT ao longo da profundidade entre as mesmas regiões.

Para obras de grande porte foi sugerida a adoção de uma das seguintes alternativas de fundações: estacas raiz de $250 \mathrm{~mm}$ e estacas hélice de $600 \mathrm{~mm}$. Caso a alternativa adotada seja estacas raiz, os comprimentos estimados variaram de 7 a $16 \mathrm{~m}$. Quando adotada a alternativa de estacas hélice, os comprimentos alteram de 7 a $19 \mathrm{~m}$.

Portanto, a carta de fundações gerada mostrou-se adequada para orientação de futuras investigações geotécnicas na região centro-norte da cidade de Fortaleza-CE.

\section{REFERÊNCIAS}

ANTUNES, W. R. e CABRAL, D. A. Capacidade de carga de estacas hélice contínua. In: Seminário de Engenharia de Fundações Especiais e Geotecnia, 3., 1996, São Paulo. Anais... São Paulo: ABMS, 1996.

AOKI, N. E VELlOSO, D. A. An approximate method to estimate the bearing caacity of piles. In: Panamerican Conference on Soil Mechanics and Foundation Engineering, 5.,1975, Buenos Aires. Anais... Buenos Aires: ISSMFE, 1975.

ASSOCIAÇÃO BRASILEIRA DE NORMAS TÉCNICAS. NBR 6484: Sondagem de simples reconhecimento com SPT - Método de Ensaio. Rio de Janeiro, p.8. 2001. 
BARROSO, S. H. A. Estudo dos Solos da Região Metropolitana de Fortaleza para Aplicação na Engenharia Rodoviária. 2002. Tese (Doutorado em Geotecnia) - Escola de Engenharia de São Carlos, Universidade de São Paulo, São Carlos, 2002.

BORGES, M. V. Cartografia Geotécnica da Cidade de Rio Branco-Acre: uso de estatística descritiva, geoestatística e estatística multivariada. Tese de Doutorado, Publicação G.TD-150/2019, Departamento de Engenharia Civil e Ambiental, Universidade de Brasília, Brasília, DF, 290 p. 2019.

BRAGA, V. D. de F. Estudo dos Tipos de Fundações de edifícios de múltiplos pavimentos na Região Metropolitana de Fortaleza. Trabalho de conclusão de curso (Graduação em Engenharia Civil) - Universidade Federal do Ceará, Fortaleza, 2009.

CABRAL, D. A. O uso da estaca raiz como fundação de obras normais. In: Congresso Brasileiro de Mecânica dos Solos e Engenharia de Fundações, 8., 1986, Porto Alegre. Anais... Porto Alegre: ABMS, 1986.

IBGE- INSTITUTO BRASILEITO DE GEOGRAFIA E ESTATÍSTICA. Censo demográfico: resultados do universo - Rio de Janeiro, RJ, 2011.

CHAVES, F. J. Caracterização Geotécnica de Solos da Formação Barreiras, da Região Metropolitana de Fortaleza para Aplicação em Obras Rodoviárias. 2000. Dissertação (Mestrado em Engenharia Civil) - Instituto Alberto Luiz Coimbra de Pós-Graduação e Pesquisa de Engenharia, Universidade Federal do Rio de Janeiro, Rio de Janeiro, 2000.

COLARES, J. Q. dos S. Mapeamento Geotécnico preliminar da Região Metropolitana de Fortaleza (CE) - Escala 1:100.000 1996. Dissertação (Mestrado em Geociências e Meio Ambiente) - Instituto de Geociencias e Ciências Exatas Universidade Estadual Paulista, Rio Claro. 1996.

DECOURT, L.; QUARESMA, A. R. Capacidade de carga de estacas a partir de valores de SPT. In: Congresso Brasileiro de Mecânica dos Solos e Engenharia de Fundações, 6., 1978, Rio de Janeiro. Anais... Rio de Janeiro: ABMS, 1978.

FONTELES, H. R. N. Caracterização Geotécnica do subsolo da porção nordeste do município de Fortaleza-CE com base em Geoestatística. 2003. Dissertação (Mestrado em Geotecnia) - Escola de Engenharia de São Carlos, Universidade de São Paulo, São Carlos, 2003.

JOLY, F. A Cartografia. Trad. Tânia Pellegrini. Campinas: Papirus, 1990.

MARTINS, A. H. C. Mapeamento Geotécnico do Setor Norte do Município de Goiânia em Escala 1:25000. 2005. Dissertação (Mestrado em Engenharia Civil) - Faculdade de Engenharia Civil, Universidade Federal de Uberlândia, Uberlândia, 2005.
MIRANDA, A. N. Prática de fundações no Ceará. In: GUSMÃO, A.D.; GUSMÃO FILHO, J.A.; OLIVEIRA, J.T.R.; MAIA, G.B. Geotecnia no Nordeste. Recife: UFPE, 2005.

MONTEIRO, P. F. Capacidade de carga de estacas - método Aoki-Velloso: relatório interno de estacas Franki Ltda. São Paulo,1997.

MOURA, A. S. Caracterização Geotécnica para projetos de fundações de edifícios em Fortaleza-CE. 1997. Dissertação (Mestrado em Geotecnia) -, Faculdade de Tecnologia, Universidade de Brasília, Brasília, 1997.

NASCIMENTO, C. B. E LARIOS, M. R. B. Cartas Geotécnicas: Desenvolvimento de Software Gerador de Perfil de Resistência à Penetração do Subsolodo UNASP-EC. Caminhos de Geografia. v.21, n.73, 321-331p. 2020.

PIMENTEL, H. W. Banco de Dados Georeferenciado e Carta Geotécnica Preliminar de Fundações da Região CentroNorte de Fortaleza-CE com base em Geoestatística. 2015. Dissertação (Mestrado em Engenharia Civil) -, Programa de Pós Graduação em Engenharia Civil, Universidade Federal do Ceará, Fortaleza, 2015.

SILVA, C.P.L. Cartografia Geotécnica Tridimensional do Setor Noroeste de Brasília. Tese de Doutorado, Publicação G.TD072/2011, Departamento de Engenharia Civil e Ambiental, Universidade de Brasília, Brasília, DF, 265 p. 2011.

THIESEN, S. Aplicação de ferramenta SIG para mapeamento geotécnico e cartas de aptidão para fundação a partir de ensaios SPT: um estudo de caso em Blumenau/SC. 2016. Dissertação (Mestrado em Engenharia Civil) -, Programa de Pós Graduação em Engenharia Civil, Universidade Federal de Santa Catarina, Florianópolis, 207 p. 2016.

VELLOSO, D. de A. e LOPES, F. de R. Fundações (Critérios de Projeto, Investigação do subsolo, Fundações Superficiais e Fundações Profundas) - Volume único. São Paulo: Oficina de Textos, 2010.

ZUQUETTE, L. V. Análise crítica da cartografia geotécnica e proposta metodológica para condições brasileiras.1987.Tese (Doutorado em Geotecnia) - Escola de Engenharia de São Carlos, Universidade de São Paulo, São Carlos, 1987.

\section{AGRADECIMENTOS}

Os autores do artigo agradecem ao Programa de PósGraduação em Engenharia Civil (POSDEHA) da Universidade Federal do Ceará (UFC), à CAPES e às empresas FUNDAÇÕES LTDA e GEOBRASIL LTDA que, gentilmente, cederam dados para a realização da presente pesquisa.

Recebido em: 30/07/2019

Aceito para publicação em: 11/08/2020 